\title{
Management of respiratory tract infections in children
}

\author{
This article was published in the following Dove Press journal: \\ Nursing: Research and Reviews \\ 12 December 2014 \\ Number of times this article has been viewed
}

\author{
Siba Prosad Paul' \\ Rachel Wilkinson ${ }^{2}$ \\ Christine Routley ${ }^{3}$ \\ 'Southmead Hospital, Bristol, \\ ${ }^{2}$ St Richard's Hospital, Chichester, \\ ${ }^{3}$ Paediatric Services, Yeovil District \\ Hospital, Yeovil, UK
}

Correspondence: Siba Prosad Paul Department of Neonatal Medicine, Southmead Hospital, Southmead Road, Westbury-on-Trym, Bristol, BSIO 5NB, UK

Email siba_prosad@yahoo.co.uk
Abstract: Respiratory tract infections (RTIs) in children are one of the most common reasons for parents consulting health professionals. Most RTIs are self-limiting viral illnesses that will resolve with time and supportive management. However, it is important for the health professional to identify any RTI that may have more serious implications for the child and require medical intervention. Diagnosis can usually be made from the history and presenting symptoms such as cough, wheeze, tachypnea, fever, or stridor. Exclusion of "red flag" symptoms will enable health professionals to appropriately reassure parents and advise symptomatic management with antipyretics and adequate fluid administration. With the expanding role of nurses in ambulatory settings, many children are now being seen by health professionals other than doctors, (eg, advanced nurse practitioners), some of whom are trained in pediatrics while others have limited knowledge of nursing sick children. It is therefore vital that these professionals remain aware of any risk factors and that they can recognize "red flags" in a sick child rapidly and escalate further management appropriately. Some children will require admission to hospital for respiratory support and other therapies, such as intravenous antibiotics and fluids. With advancement of the "non-medical prescriber" within the nursing profession, awareness of when to give or not give antibiotic therapy needs careful consideration, especially in light of the problems that may arise from overuse of antibiotic treatment. Nurses have a vital role, not only in administering medications and supporting other medical interventions, but also in supporting the child and family over the period of illness. The education of the parents and the child, in some instances, about prevention and avoidance to reduce the risks of any further RTIs must be addressed, including immunization and smoking cessation.

Keywords: respiratory tract infections, children, red flags, holistic care, immunization

\section{Introduction}

Respiratory tract infections (RTI) in children are one of the most common reasons for consulting a health professional. ${ }^{1}$ RTIs are usually manifested by a combination of rhinitis, cough, sore throat, wheeze, and fever. The vast majority of these infections in children are managed in the primary care setting, with only a small number needing hospital admission. Acute RTI is one of the leading causes of childhood mortality. Data from the Office of National Statistics for England and Wales (for 2008 and 2009) show that RTIs accounted for around 4\% of all deaths in children aged $0-14$ years. ${ }^{2}$ This paper discusses the risk factors that health professionals assessing children should be aware of, as they can play an important role in identifying "sick" children earlier, thereby escalating further assessment by a pediatric specialist sooner, and in identifying the child who can be managed safely with reassurance and advice in their own home. There is also a discussion of the part respiratory nurse specialists can play and the increasing 
importance of their role in managing a significant proportion of children with chronic respiratory conditions in the community by providing support and expert advice.

Although many of the symptoms of RTIs cross the boundaries of multiple conditions, in this paper the authors describe the common RTIs that a health professional assessing children will encounter and discuss pertinent "red flags" and treatment of these conditions and also appropriate "safety net" advice for families.

\section{Basic anatomy and physiology of the respiratory tract}

The respiratory tract starts at the nasal cavity and ends in the alveoli (in the lungs). However, for easier description and understanding of pathologies, it can be divided into two parts. The upper respiratory tract refers to the structures of the respiratory system that lie outside the thorax or above the sternal angle, and consists of the nasal cavity and pharynx (including tonsils) through to the larynx. The lower respiratory tract begins with the trachea and also includes the bronchi and lungs. Cough and wheeze are predominantly described with a lower RTI while stridor is typically noted in an upper RTI. ${ }^{3}$ It is important to remember that a mixture of symptoms is often seen in children, and it may be difficult to label the presentation as an upper or lower RTI.

RTIs are more common in the winter months, and this is likely due to children being in close proximity to each another as they tend to stay indoors more often. ${ }^{2,4,5}$ Unlike in adult practice, it is extremely important to remember that a child's respiratory rate and heart rate will vary with age and the parameters are likely to be different from that in a normal adult. Health professionals need to compare a child's vital parameters (heart and respiratory rate) with the levels highlighted in Table 1 before labeling these are abnormal for that specific age group.

\section{Red flag signs in children with RTI}

Unlike adults, children with a respiratory illness deteriorate more rapidly, and respiratory arrest needing resuscitation is

Table I Respiratory and heart rates in children at rest

\begin{tabular}{lll}
\hline Age (years) & $\begin{array}{l}\text { Respiratory rate } \\
\text { (per minute) }\end{array}$ & $\begin{array}{l}\text { Heart rate } \\
\text { (per minute) }\end{array}$ \\
\hline$<1$ & $30-40$ & $110-160$ \\
$1-2$ & $25-35$ & $100-150$ \\
$2-5$ & $25-30$ & $95-140$ \\
$5-12$ & $20-25$ & $80-120$ \\
$>12$ & $15-20$ & $60-100$ \\
\hline
\end{tabular}

Note: Adapted from the Advanced Paediatric Life Support: The Practical Approach, 5th Edition, Advanced Life Support Group; edited by Martin Samuels, Susan Wieteska. ${ }^{60}$ Copyright $\odot$ 201 I, John Wiley and Sons. usually the primary event. There are a number of reasons why children are more vulnerable to RTIs, ${ }^{1,2,4,6,7}$ and these are highlighted in Figure 1.

It is important that health professionals assessing children with a RTI identify any "red flags", as this will enable them to plan the necessary management of the child at an appropriate level. ${ }^{2,5,6}$ The presence of one or a combination of these signs should prompt health professionals in the community to refer children early to secondary care services. Further, health professionals in hospitals should be extra careful in discharging such children, or those with known risk factors for developing RTI (Figure 2) 2,5,6,8 even if the initial presentation may be considered to be mild to moderate. The most common "red flag" signs are highlighted in Figure 3.

\section{Community-acquired pneumonia}

Community-acquired pneumonia (CAP) is defined as an inflammatory condition of the lungs resulting from an infection acquired in the community (ie, outside the hospital environment). The overall incidence of CAP in children aged 0-16 years was found to be 14.4 per 10,000 per year in a prospective population-based study in 13 hospitals in the north of England. ${ }^{9}$ However, this incidence was much higher in children under 5 years of age (33.8 per 10,000 children per annum). ${ }^{9}$ CAP presents with fever and signs of respiratory distress, such as tachypnea, cough, chest wall recession, and crackles may be felt on palpation of the chest. ${ }^{10}$

It is important to note that viruses account for $30 \%-67 \%$ of cases of CAP in childhood, and are more frequently identified in children aged younger than 1 year in comparison to those aged older than 2 years. ${ }^{5}$ The viruses most frequently encountered in clinical practice are respiratory syncytial virus (RSV), rhinovirus, parainfluenza and influenza viruses, and human metapneumovirus. The most common bacterium causing CAP is Streptococcus pneumoniae, while Mycoplasma pneumoniae is not uncommon in children aged older than 5 years. ${ }^{5}$ Combinations of viral and bacterial pathogens are also not uncommon in clinical practice. ${ }^{5}$

Children with symptoms of probable CAP should be referred for assessment to a medical professional or a respiratory nurse specialist, and can generally be safely managed in the community with advice regarding fluids and antipyretics along with "safety net" advice regarding what to do if the child deteriorates at home. A chest X-ray does not differentiate between a bacterial and viral etiology, but may be done to substantiate or confirm the clinical suspicion of pneumonia in an unwell child in secondary care where the pathology may not be clear. ${ }^{11}$ The British Thoracic Society suggests that if 
- Shorter respiratory tract as compared with that of adults, leading to faster spread of infection

- Lack of interconnectivity in the lower airways and a lower functional reserve in children, causing rapid compromise of the airway and deterioration of symptoms

- Absence of breast feeding

- Increased exposure to respiratory pathogens from older siblings and other children while attending childcare facilities; however, this helps to build up immunity against pathogens in the long term

- Environmental risk factors, such as exposure to passive smoking and other environmental pollutants

- Symptoms interpreted and reported by parents, and may not always be accurate

- Young children usually have 3-8 episodes of respiratory illness per year (this may cause increased anxiety among parents who may be looking for serious pathologies and lead to children being unnecessarily investigated)

- Acquired immunity has not developed in young infants

- Defects in the immune system and familial predisposition

Figure I Reasons for increased vulnerability in children with respiratory tract infections.

Note: Adapted from Schaad,' Paul et al, ${ }^{2}$ NHS Choices 201 I,${ }^{4}$ SIGN 2006, ${ }^{6}$ and Snellman et al. ${ }^{7}$

Abbreviations: NHS, National Health Service; SIGN, Scottish Intercollegiate Guidelines Network.

clinical signs of CAP are evident in a systemically well child in the community, they do not need a chest X-ray. ${ }^{12}$

It is important to note that antibiotics are only effective in treating bacterial infections, and in viral chest infections, use of antibiotics will not cure or shorten the length of the illness. ${ }^{7}$ Inappropriate use of antibiotics may cause side effects, such as gastrointestinal discomfort, diarrhea, allergic reactions, nappy rash, and yeast infections, and there is risk for development of antibiotic-resistant strains of bacteria. ${ }^{7}$ In cases where an antibiotic is considered necessary, amoxicillin should be the first choice for oral therapy. ${ }^{12}$ Macrolide antibiotics, such as erythromycin or azithromycin, should be reserved for those with penicillin allergy or where there has been no response to first-line empirical amoxicillin therapy. ${ }^{12}$ In a retrospective cohort study in the USA, ${ }^{13}$ where 17,299 pneumonia cases in children aged 1-17 years were treated in 125 hospitals between 2007 and 2010, extremely low rates of narrow-spectrum antibiotic use were noted $(0.2 \%$ penicillin/ampicillin and $7.4 \%$ macrolides), and following this review, the authors suggested a need for tailored antibiotic stewardship. ${ }^{13}$

Childhood vaccinations for Haemophilus influenzae type $\mathrm{B}$ and pneumococcal vaccines are considered to be preventative. ${ }^{2}$ Health professionals play an extremely important role in improving vaccination uptake in general by providing accurate information about the benefits of vaccines and by dispelling myths. They should specifically encourage

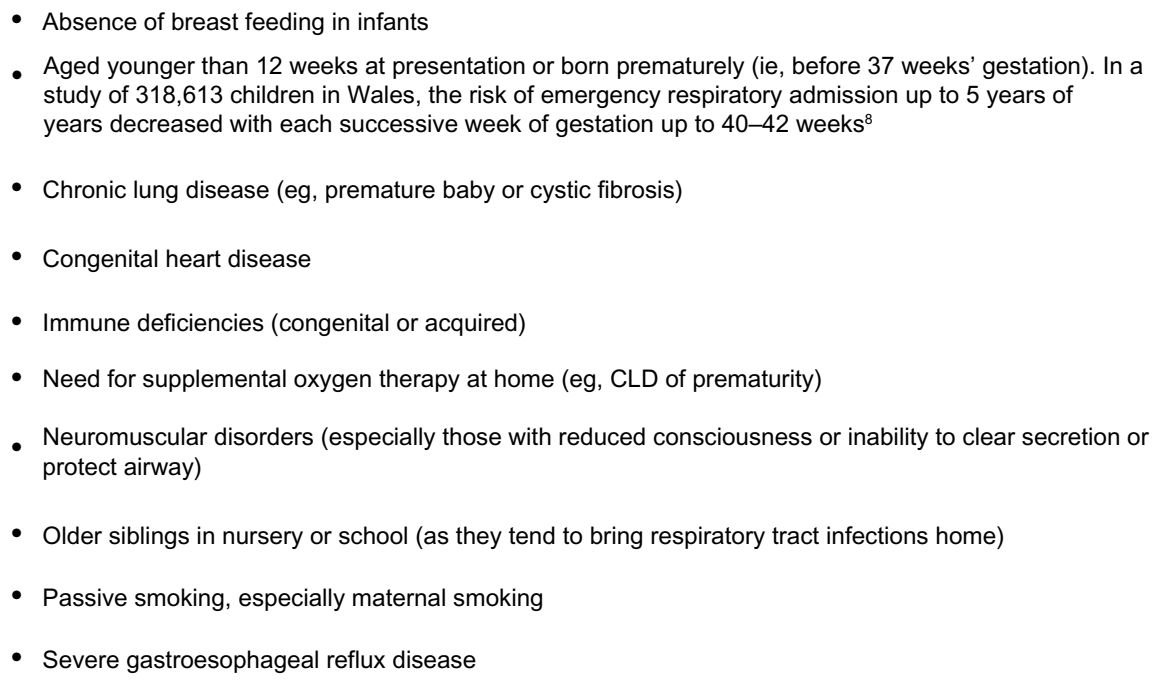

Figure 2 Risk factors for respiratory tract infection.

Note: Adapted from Paul et al, ${ }^{2}$ Harris et al, ${ }^{5}$ the Scottish Intercollegiate Guidelines Network, ${ }^{6}$ and Paranjothy et al. ${ }^{8}$ Abbreviation: CLD, chronic lung disease. 
parents with children (along with siblings) who have missed immunization and suffered an episode of pneumonia. ${ }^{10}$

\section{Bronchiolitis}

Bronchiolitis is defined as an inflammation of the bronchioles, which are the smallest air passages in the lungs. Bronchiolitis most commonly affects infants and young children, the peak age being 3-6 months. ${ }^{6}$ In 2005, it has been estimated that 66,000-199,000 children aged younger than 5 years died from RSV-associated acute lower RTI, and 99\% of these deaths occurred in developing countries. ${ }^{14}$

Bronchiolitis is a viral RTI characterized by fever, nasal discharge, coughing, and wheeze. ${ }^{15}$ Other features that may be seen include apnea (particularly in premature babies, and in young infants this may be the first sign), poor feeding, dehydration, and fever. ${ }^{15,16} \mathrm{RSV}$ is the most common causative organism and is responsible for around $75 \%$ of all cases. ${ }^{6}$ Rhinovirus is responsible for about $25 \%$ cases of bronchiolitis; other viruses have a minimal role. It is estimated that around $70 \%$ of all infants are infected with RSV in their first year of life, and $22 \%$ will develop symptomatic disease. ${ }^{6}$

Diagnosis of bronchiolitis is made clinically from the history and physical examination. Young infants and children with risk factors (Figure 2) are at higher risk of deterioration, and are likely to benefit from early assessment by a medical professional or a nurse specialist. Most children with bronchiolitis are managed symptomatically in the community with small volume oral feeds given more often, nasal saline drops, and raising the head end of the mattress. ${ }^{15}$ Measurement of oxygen saturation is important, given that saturation of $<92 \%$ in air is a definite indication for admission to hospital. ${ }^{6}$
Some children will need hospitalization for bronchiolitis and are generally managed conservatively with nasogastric tube feeds (or intravenous fluids) and supplemental oxygen administration. A small number of hospitalized infants may need advanced respiratory support in the form of continuous positive airway pressure support or ventilation. ${ }^{17}$

The role of bronchodilators remains controversial, although some studies have highlighted minimal short-term benefits. A recent Cochrane review did not support use of bronchodilators in the routine management of bronchiolitis. ${ }^{18}$ A randomized controlled study found nebulization with hypertonic saline ( $3 \%$ or $6 \%$ sodium chloride) to be safe but this did not reduce the length of stay in hospital, duration of supplemental oxygen, or nasogastric tube feeding in children hospitalized with moderate-to-severe viral bronchiolitis, and its routine use is not recommended..$^{19} \mathrm{~A}$ single dose of bronchodilator therapy may be used on a trial basis in severe cases, with monitoring of response and continuation of further doses may be decided on the basis of the initial response.

Antibiotics should be reserved for selected cases in severely ill hospitalized infants with bronchiolitis where secondary bacterial infection is suspected. A Cochrane review involving 543 infants found minimal evidence to support the routine use of antibiotics in bronchiolitis; their use should be reserved for infants who have deteriorated enough to require continuous positive airway pressure support or mechanical ventilation. ${ }^{20,21}$ Infants in the community being treated for bronchiolitis should not be treated with antibiotics or bronchodilators.

Children in the high-risk group (Figure 2) such as those with chronic lung disease (CLD) of prematurity or congenital

\footnotetext{
- Rapid respiratory rate

- Difficulty in breathing; intercostal, subcostal (and sternal) recessions

- Intermittent apnea (cessation of external breathing manifested by pauses in chest wall movement) or grunting (protective mechanism of the body to keep air in the lungs so they will stay open, heard in expiration)

- Children with risk factors for respiratory tract infection which potentially will lead to faster deterioration

- Infants who have fed less than $50 \%$ of expected daily requirement in the preceding 24 hours and/or are deemed to be clinically dehydrated (fast heart rate, minimal or no urine output [may be difficult to interpret if there is concurrent diarrhea] or vomiting)

- Family judged (by the health professional) as being unable to safely observe or supervise the child appropriately during the illness; this may be due to parental illness, drug/alcohol abuse, learning disabilities, and adverse social circumstances, or may be due to the complexity of other associated health issues in the child
}

Figure 3 Red flag signs in children with respiratory tract infections. 
heart disease may, be offered passive protection by the monoclonal antibody palavizumab administration over the winter months. ${ }^{6}$ A review in the tertiary neonatal unit at Coombe Women and Infants University Hospital, Dublin, UK, found that involving a clinical nurse specialist dedicated to RSV prevention and prophylaxis prior to discharge from the neonatal unit improved parental satisfaction and compliance, which in turn proved effective in the success of the RSV infection prevention plan. ${ }^{16}$

\section{Preschool (viral) wheeze}

Preschool wheeze, also known as "viral-induced wheeze" (VIW), is defined as intermittent airway obstruction manifested by cough and wheeze. Wheeze is defined as expiratory breathing difficulty with a high-pitched sound audible during expiration. Wheezing is a common symptom in preschool children, and most often these episodes are not due to asthma. Recurrent preschool wheeze is also common, with 16\%-29\% (UK) and around 48\% (USA) of children reported to have suffered one episode of wheeze by 6 years of age. ${ }^{22,23}$ It is usually divided into two categories, ie, episodic viral wheeze (EVW) and multitrigger wheeze (MTW). ${ }^{23}$

Cough and wheezing in EVW is always triggered off by a viral infection and may be associated with fever and coryzal symptoms. Children with EVW do not have any interval symptoms between episodes. The cough occasionally may be severe enough to induce vomiting. ${ }^{2}$ Rhinoviruses cause most cases of VIW; other causative viruses include adenovirus, influenza, parainfluenza, or RSV. ${ }^{24}$ The most important trigger for MTW is a viral infection, although these children also wheeze in response to other triggers, such as exercise, allergen exposure, passive smoking, and exposure to cold air, ${ }^{23}$ and do have interval symptoms between episodes of viral infection.

Most children presenting with preschool wheeze can be managed with parental reassurance, adequate hydration, and symptomatic management. A trial of bronchodilators may be helpful, and these are the mainstay of treatment in most cases of EVW. ${ }^{23}$ Children with MTW may need inhaled corticosteroids to minimize interval symptoms but does not modify the course of the disease or prevent development of asthma. ${ }^{23}$ Factors known to be beneficial in preventing recurrences of preschool wheeze are childhood vaccinations and avoidance of passive (tobacco) smoking. ${ }^{25}$

Most children with EVW are likely to outgrow their wheezy symptoms by the end of the preschool years. However, remission of atopic MTW is often not achieved, and these children may go on to develop asthma in later life..$^{23,25}$

\section{Laryngotracheobronchitis (croup), bacterial tracheitis, and epiglottitis}

Croup is considered to be an upper airway condition in which diffuse inflammation with exudate and edema narrows the subglottic area of the airway. It is manifested by a brassy, seal-like, barking cough along with hoarseness of voice and restlessness, and generally develops in the second year of life. ${ }^{26}$ In a study of 327 children hospitalized with croup, the median age at presentation was 16.7 months. ${ }^{27}$ A prodrome of low-grade pyrexia, coryzal symptoms, and a mild cough may precede the main symptoms of croup in some cases. Inspiratory stridor may develop in some children, and becomes prominent when the child cries or becomes upset. ${ }^{26}$

Croup is predominantly caused by parainfluenza virus, although viruses such as influenza $A$ are also known to cause viral croup. ${ }^{26}$ Although these symptoms are distressing for both the child and parents, the child is usually not seriously ill and in most cases can be managed in the community with supportive management. Children with only the barking cough may be managed safely at home with rehydration and antipyretics (particularly ibuprofen for its anti-inflammatory properties) and safety net advice to seek urgent medical advice if the child deteriorates or develops stridor. If the symptoms recur, the parents should be advised to move the child to somewhere where they can inhale cool air to reduce the inflammation in their upper airway and this may help to releive their symptoms.

On the other hand, when a child with stridor presents with a raised temperature, drooling of saliva, or a toxic appearance, bacterial tracheitis or epiglottitis should be suspected, with urgent transfer to hospital. A study of 203 children from Australia $^{28}$ aimed at differentiating symptoms predictive of croup $(n=102)$ from epiglottitis $(n=101)$ early in the illness found that both illnesses presented with stridor, but cough and absence of drooling suggested croup whereas drooling with absence of cough were more likely to be epiglottitis. Cases of epiglottitis have been substantially reduced since the introduction of $H$. influenzae type B vaccine, so it is important to enquire about the child's immunization history when they present with a stridor. This is especially important in children who have recently immigrated from a developing country, not immunized or appears extremely unwell/toxic with croup like symptoms.

Children with stridor or other risk factors (Figure 2) should be urgently reviewed by a medical professional or an advanced nurse practitioner. Admission to hospital should be considered, and children with viral croup may benefit from a short course of oral steroids such as dexamethasone 
(or prednisolone), which helps in reducing airway inflammation. In a study of 327 children with 365 hospitalization episodes for croup, $48 \%$ were given a dose of systemic corticosteroids post admission to hospital. ${ }^{27}$ A need for nebulized adrenaline could not be predicted by demographics, past history, or presenting vital signs. The median length of stay in the study group was 31.7 hours. ${ }^{27}$ However, children who presented with lower oxygen saturations, a past history of croup, or intubation were more likely to need a prolonged stay in hospital or have a complicated course of croup. ${ }^{27}$

Children in whom bacterial tracheitis is suspected should be admitted and managed in a high-dependency environment with close monitoring because these children can potentially deteriorate rapidly and may require urgent invasive airway support. ${ }^{29}$ This group of children should be treated with a prolonged course of broad-spectrum antibiotics and may require surgical intervention in the form of direct laryngoscopy, bronchoscopy, and debridement of mucopurulent debris. ${ }^{29}$

Epiglottitis is a medical emergency, and nurses in the emergency department should aim to keep the child comfortable, minimize distress by not separating the child from the parent, avoid painful procedures, and perform limited observations from a distance (trying to do saturations, attaching electrocardiographic leads, and taking temperatures may be counterproductive). ${ }^{2}$ Senior pediatric, anesthetic, and ear, nose, and throat consultant support should be urgently summoned because emergency tracheostomy may be necessary in some cases (where tracheal intubation is unsuccessful). These children will be best managed in the pediatric intensive care setting, will need broad-spectrum antibiotics, and may need other supportive measures, such as ventilation and intravenous fluids. Any missed immunizations should be encouraged once the child has improved and is ready for discharge. ${ }^{2}$

\section{Chronic lung disease of prematurity}

CLD of prematurity is defined as a need for supplemental oxygen by 28 days of life or by 36 weeks of corrected gestational age, whichever date is reached earlier. ${ }^{30}$ CLD usually occurs in infants who are born extremely premature (usually $<32$ weeks) with a low birth weight (usually $<1.5 \mathrm{~kg}){ }^{30}$

These children are often discharged home on supplemental oxygen to keep their oxygen saturation at more than 93\%-95\%. They are also at higher risk of developing RTIs such as bronchiolitis, croup, and CAP. ${ }^{2}$ Children with CLD with signs of respiratory illnesses, apnea, and requiring increased supplemental oxygen should be referred urgently to hospital. ${ }^{30}$
This group of children often may have missed their routine immunizations and nurses play an important role in arranging catch-up immunizations. Health professionals should remain aware of the possible challenges that parents of infants with CLD may face in the community, so as to appropriately reassure or refer early to specialist services. ${ }^{2}$ It is also important that neonatal community nurses support parents in the community through regular home visits, arranging a ready supply of medicines or special feeds at home and disability living allowances. In a US study of 150 premature neonates who were randomly assigned to either community-based $(n=75)$ or hospital-based $(n=75)$ follow-up, both groups had similar developmental and health outcomes. ${ }^{31}$ It is also necessary to ensure that hospital outpatient appointments with different professionals are attended and that any developmental concern identified (which is more likely in these children) is highlighted early to appropriate professionals (developmental pediatricians). Community neonatal nurse support is common in the UK set-up, and is particularly helpful for families living in rural settings and families for whom access to a tertiary care medical facility is difficult.

However, it is not uncommon for these children to get admitted with RTIs. Health professionals should refer these children early to the hospital in situations where a need for escalation of respiratory support becomes evident. While the medical management will be decided by the actual pathology of the respiratory illness, these children are better managed in a pediatric high-dependency set-up as they have the potential to deteriorate earlier. The pediatric early warning score (PEWS) is an established tool used in UK clinical practice. In a multicenter study of 2,074 patients in Canada, it was found that the PEWS was elevated and continued to increase in the preceding 24 hours before the clinical deterioration event. ${ }^{32}$ In our clinical experience, use of the PEWS in the care of patients with CLD admitted with respiratory deterioration has been found to be helpful, although testing in a large clinical set-up (or multicenter involvement) is necessary to determine whether this score will improve quality of care and patient outcomes.

\section{Tonsillitis}

Tonsillitis is defined as an inflammation of the tonsils and is a common upper RTI in children. The etiology is usually a viral pathogen; however, bacterial pathogens such as Group A streptococcus are also known to cause tonsillitis. Tonsillitis usually presents with a sore throat that can feel worse when swallowing, high temperature $\left(>38^{\circ} \mathrm{C}\right)$, coughing, hoarseness of voice, and headache. ${ }^{33}$ Symptoms usually last for 3-4 days before the child recovers. 
Most children with tonsillitis can be safely managed in the community and will need symptomatic management with adequate fluids, antipyretics, and reassurance. Children with tonsillitis who have prolonged symptoms (for more than 4 days), are unable to eat or drink properly, or have other risk factors (Figure 2) should be reviewed by a medical professional or advanced nurse practitioner. ${ }^{33}$

It is important that antibiotics are not prescribed haphazardly, and the presence of three or four Centor criteria (history of fever, tonsillar exudates, no cough, tender anterior cervical lymphadenopathy) may be used as a guide to consider prescription of antibiotics. ${ }^{34}$ The higher the score, the greater the probability that the throat infection has been caused by Group A Streptococcus.

In cases where antibiotic therapy is deemed to be necessary, oral phenoxymethylpenicillin is the drug of choice and should be prescribed for 10 days. ${ }^{34,35}$ A throat swab may be obtained before commencing antibiotics. Inpatient admission will be required for patients with sore throat who have stridor, progressive difficulty with swallowing, increasing pain, or severe systemic symptoms. ${ }^{34}$ These patients will need intravenous antibiotics if they are unable to tolerate oral medicines or there is associated vomiting.

Peritonsillar cellulitis or abscess (quinsy) should be suspected when children present acutely to a pediatrician or an ear, nose, and throat service. They may require parenteral antibiotics. In adolescents and young adults, sore throat due to glandular fever (infectious mononucleosis) caused by Epstein-Barr virus is a common reason for hospital admission, as these patients are often unable to swallow. ${ }^{34}$

The indications for tonsillectomy in children are not clear, and no study has demonstrated clear clinical benefits of tonsillectomy in children with recurrent sore throats. In absence of clear evidence, it is suggested that the benefit of tonsillectomy in children increases with the severity and frequency of sore throats prior to tonsillectomy. Figure 4 highlights the current indications for consideration of tonsillectomy for recurrent acute sore throat in both children and adults. ${ }^{34}$ Adenotonsillectomy may be required in children with obstructive sleep apnea and other rare conditions, such as periodic fever, but further discussion is beyond the scope of this paper.

Lemierre's syndrome (caused by Fusobacterium) should be suspected in previously healthy children and adolescents who suffer an acute episode of intensely painful sore throat with high fever lasting a few days along with swollen neck glands. ${ }^{36}$ This is a re-emerging condition and is being seen more commonly in present times. These children will need admission to hospital and multiple intravenous antibiotics, and heparin therapy may also be necessary. ${ }^{36}$

\section{Otitis media and mastoiditis}

Otitis media (OM) is defined as an inflammation of the middle ear and is characterized by the accumulation of infected fluid in the middle ear, a bulging tympanic membrane (TM), and pain in the ear. When the TM becomes perforated, drainage of pus into the external ear canal is seen. This is the leading reason why antibiotics are prescribed for children and also the need for undergoing a surgical procedure, ie, grommet insertion. ${ }^{37} \mathrm{~A}$ review of epidemiological studies in indigenous Australian children, ${ }^{38}$ poor community and domestic infrastructure, overcrowding, and exposure to tobacco smoke were identified to increase the risk of OM. The same review reported a prevalence of $7.1 \%-12.8 \%$ for the OM subtypes, $10.5 \%-30.3 \%$ for active chronic $\mathrm{OM}$, and $31 \%-50 \%$ for TM perforation. ${ }^{38}$

The latest American Academy of Pediatrics and American Academy of Family Physicians guidelines have narrowed down the diagnostic criteria for acute $\mathrm{OM}$ in children and allows its distinction from OM with effusion. ${ }^{37}$ Diagnosis of acute $\mathrm{OM}$ requires the presence of middle ear effusion (air-fluid level behind the TM, impaired TM mobility on pneumatic otoscopy, or otorrhea signifying TM perforation) with acute onset of signs and symptoms of middle ear inflammation. Acute $\mathrm{OM}$ can be reliably distinguished from OM with effusion by the addition of "cloudy" and moderateto-severe bulging of the TM; less specific signs include significant TM erythema or hemorrhage. ${ }^{37}$

Upper RTI (both viral and bacterial) can lead to the development of acute OM due to mucosal inflammation, leading

\footnotetext{
- Episodes of sore throats are due to acute tonsillitis

- Episodes of sore throat are disabling and prevent normal functioning

- Seven or more well documented, clinically significant, adequately treated sore throats in the preceding year, five or more such episodes in each of the preceding 2 years, or three or more such episodes in each of the preceding 3 years
}

Figure 4 Consider referral for tonsillectomy

Note: Adapted from the Scottish Intercollegiate Guidelines Network. ${ }^{34}$ 
to adenoidal hypertrophy, Eustachian tube dysfunction, and disruption of mucociliary defences. ${ }^{37}$ The initial event leading to $\mathrm{OM}$ in humans is considered to be nasopharyngeal colonization with potential middle ear pathogens. S. pneumoniae and $H$. influenzae has been classically identified as the primary bacterial pathogens. However, PCV7-unrelated S. pneumoniae and $H$. influenzae non-type B are likely to be seen more often in countries where immunizations have been available. ${ }^{37}$

Most cases of OM in children can be managed in the community, with reassurance, antipyretics, and antibiotics (where bacterial pathology is suspected). Investigations are usually not indicated. In some countries, tympanometry is done by general practitioners and nurses, and a flat curve may indicate acute OM. In a Danish study of 954 children ( 0 -7 years) seen in primary care, a flat tympanometry curve was statistically associated with prescribing antibiotics for acute OM in the older children ( $>2$ years). ${ }^{39}$ Pus culture may be indicated where there is chronic OM, recurrent perforations, and in children with grommets. A study of outpatient antibiotic use in 26 countries in Europe noted a shift from the old narrowspectrum antibiotics to the newer broad-spectrum antibiotics, eg, amoxicillin and clavulanic acid. ${ }^{40}$ A 5-day course of oral amoxicillin or erythromycin should be adequate to treat acute OM in children. ${ }^{41}$ Antibiotics should be considered in cases where the following symptoms are present:

- symptoms have persisted for more than 2-3 days

- children aged $<2$ years with bilateral acute OM or bulging TM and four or more symptoms

- children of any age presenting with otorrhea

- patients at high risk of complications, eg, significant heart, lung, renal, liver, or neuromuscular disease, immunosuppression, or cystic fibrosis, and young children who were born prematurely. ${ }^{41}$

It is important to identify the complications associated with OM. These include labyrinthitis, meningitis, intracranial sepsis, and facial nerve palsy. Recurrent episodes may lead to TM scarring, with permanent hearing impairment, chronic perforation and otorrhea, cholesteatoma, or mastoiditis. ${ }^{41}$ In recent years, there has been an increased incidence of mastoiditis noted, and this is possibly due to strict adherence to a "wait and watch" approach and minimizing antibiotic prescription in children with RTIs in many developed countries. ${ }^{42}$ These children will need early referral to ear, nose, and throat services for specialist management. ${ }^{42}$

\section{Protracted bacterial bronchitis}

Protracted bacterial bronchitis is defined as the presence of chronic, isolated, moist cough (lasting continuously for more than 4 weeks) without any clinical findings suggestive of an alternative diagnosis and resolution of symptoms when antibiotic therapy is given for $2-3$ weeks. ${ }^{43,44}$ In the past this has been referred to by different terminologies such as "chronic bronchitis of childhood", "protracted bronchitis", "persistent endobronchial infection", or "pre-bronchiectasis". There has been recent increased interest in the condition given that untreated protracted bacterial bronchitis can lead to bronchiectasis in some children.

Protracted bacterial bronchitis is a clinical diagnosis and is established by ruling out other serious pathologies such as undiagnosed cystic fibrosis (evidence of bronchiectasis, hyperinflation, lobar collapse) or foreign body aspiration (may show signs of air trapping, hyperinflation of one lung/ lobe or the foreign body). Chest X-ray may be useful if the cause for chronic cough is not clear from the history, in reassuring parents and will also be useful for ruling out other pathologies. ${ }^{43,44}$ Bronchoalveolar lavage has demonstrated that most commonly isolated pathogens are non-typable $H$. influenzae (49\%), S. pneumoniae (20\%), Moraxella catarrhalis (17\%), and Staphylococcus aureus (12\%). ${ }^{43}$

Management of protracted bacterial bronchitis includes an explanation about the condition, and there is a need for a prolonged course of oral antibiotics. A reasonable approach, as highlighted in the literature, is to use a trial of oral antibiotics; however, it should be explained to parents that this noninvasive treatment may not allow confirmation of a definitive diagnosis. ${ }^{43,44}$ A recent double-blind, randomized controlled study of 50 children with protracted bacterial bronchitis (wet cough of at least 3 weeks' duration) demonstrated that 2 weeks of oral co-amoxiclav can be effective. ${ }^{45}$ A 3-week course of oral antibiotics (co-amoxiclav or azithromycin) followed by a review at the end of antibiotic therapy has been found to be useful in our clinical practice. ${ }^{44}$ Bronchoscopy with bronchoalveolar lavage may be considered in children whose parents strongly insist on a definitive diagnosis at the very outset or in cases where relapse is seen after three courses of oral antibiotics. ${ }^{43,44}$

\section{Respiratory tract infections and asthma in children}

Various studies have supported a strong association between viral RTIs and episodes of exacerbation of asthma. However, the interaction between viral respiratory RTIs in infancy and childhood, and their role in the development of asthma or subsequent exacerbations is complex and intriguing. ${ }^{46}$ In a study of 2,531 children from the Oslo birth cohort who were followed from birth to 4 years of age, RTIs in early life was 
noted to increase the risk of developing bronchial obstruction during the first 2 years of life and developing asthma by 4 years of age. ${ }^{47}$ In a case-control study of 142 children with a diagnosis of asthma, 65 participants had acute asthma exacerbations and formed the study group while 77 children with well controlled asthma served as the control group. It was found that respiratory virus infection was associated with exacerbations of asthma ( $63.1 \%$ in cases versus $23.4 \%$ in controls) and rhinovirus was the most prevalent pathogen (60\% in cases versus $18.2 \%$ in controls) associated with these exacerbations. ${ }^{48}$ Another study that looked at asthma control in 654 children aged 4-18 years reported a higher numbers of RTIs in the previous 12 months in children with a lower level of asthma control. ${ }^{49}$ The same study also reported that different types of RTIs contribute equally to poorly controlled asthma.

Therapies effective against rhinovirus may decrease asthma exacerbations, and further research is necessary to find preventive measures. ${ }^{48}$ In the absence of definitive control or preventive measures for asthma, hand hygiene is considered to be the best method for preventing the spread of the common cold (ie, rhinoviruses). ${ }^{50}$ Some experts suggest that a healthy balanced diet, active probiotic supplements, and immunostimulant OM-85 may reduce recurrent RTIs in asthmatic children, which will lead to better asthma control. ${ }^{50}$

\section{Challenges in assessing a child with RTI}

Children, especially young ones, can pose challenge to health professionals while performing a clinical examination. The clinical assessment should start with a focused history, and this should include an enquiry about presenting symptoms, use of over-the-counter medicines by parents, previous medical history, relevant risk factors (Figure 2), and other comorbidities (eg, significant heart, lung, renal, liver, or neuromuscular disease, immunosuppression, cystic fibrosis, and young children who were born prematurely). ${ }^{35}$

This should be followed by a physical examination to identify relevant clinical signs to establish a diagnosis. It is important to remember that the methodical approach of inspection, palpation, percussion, and auscultation may not be applicable in young children. Observation is an extremely powerful tool for identifying a sick child, and it cannot be overemphasized that the time spent in observing the child will give a wealth of information that may not be elicited by trying to examine the child straight away, which may also further distress the sick child and lead to the child becoming uncooperative.
The clinical examination should start with recording the respiratory rate and heart rate, and both should ideally be done for 1 minute..$^{51}$ It is vital to use correct equipment to record temperature, oxygen saturations and blood pressure, because these will give valuable information regarding further management strategies for the child. An assessment of breathing effort, color, activity, abnormal breath sounds (eg, wheeze, stridor), and hydration status should also be done. It is important to identify an increased oxygen requirement in a child with CLD, and this should be considered as a sign of clinical deterioration. Further, previous scars from cardiac or lung surgeries would give an indication of previous comorbidities and help in deciding on the need for admission in a child with RTI. It is important that a child presenting with stridor is not examined with a tongue depressor because this can cause further distress and sudden airway obstruction (due to laryngospasm).

Palpation is an important aspect of clinical assessment in identifying lumps, asymmetrical chest wall movement, crepitations, apex beat (if felt on right side may indicate dextrocardia), localized tenderness, or emphysema (this may be seen in association with pneumonia in children).

Auscultation may need to be opportunistic in young children, and needs to be performed when the child is relaxed (preferably at the start of the examination). Table 2 highlights the auscultatory findings which are likely to be elicited in different RTIs. Table 3 highlights the common organisms causing RTIs in children; this will help the clinician in deciding appropriate management.

Table 2 Auscultatory findings in respiratory illnesses

\begin{tabular}{|c|c|}
\hline Condition & Auscultatory findings \\
\hline CAP & $\begin{array}{l}\text { Differential air entry, crepitations, localized wheeze } \\
\text { due to bronchospasm, decreased or no air entry in } \\
\text { CAP with consolidation }\end{array}$ \\
\hline Bronchiolitis & $\begin{array}{l}\text { Fine inspiratory crackles and/or high pitched } \\
\text { expiratory wheeze }\end{array}$ \\
\hline $\begin{array}{l}\text { Preschool viral } \\
\text { wheeze }\end{array}$ & $\begin{array}{l}\text { Wheeze (during expiration) on auscultation during } \\
\text { episodes of exacerbation in episodic viral wheeze }\end{array}$ \\
\hline $\begin{array}{l}\text { Chronic lung } \\
\text { disease of } \\
\text { prematurity }\end{array}$ & $\begin{array}{l}\text { Will depend on nature of presenting respiratory } \\
\text { tract infection, eg, fine inspiratory crackles and/ } \\
\text { or high-pitched expiratory wheeze }\end{array}$ \\
\hline Croup & $\begin{array}{l}\text { Normal or upper airway conducted noises may } \\
\text { be auscultated (during inspiration) }\end{array}$ \\
\hline Tonsillitis & $\begin{array}{l}\text { Normal or upper airway conducted noises may } \\
\text { be auscultated }\end{array}$ \\
\hline Otitis media & $\begin{array}{l}\text { Will be normal unless concurrent respiratory } \\
\text { tract infection pre-exists }\end{array}$ \\
\hline $\begin{array}{l}\text { Protracted } \\
\text { bacterial bronchitis }\end{array}$ & Normal \\
\hline
\end{tabular}

Abbreviation: CAP, community-acquired pneumonia. 
Table 3 Types of respiratory tract infections and common causative organisms

\begin{tabular}{|c|c|c|}
\hline Condition & Viral organism & Bacterial organism \\
\hline $\begin{array}{l}\text { Community-acquired } \\
\text { pneumonia }\end{array}$ & RSV, rhinovirus & $\begin{array}{l}\text { Streptococcus pneumoniae, } \\
\text { Mycoplasma pneumoniae }\end{array}$ \\
\hline Bronchiolitis & RSV, rhinovirus & Not applicable \\
\hline Preschool (viral) wheeze & Rhinovirus & Not applicable \\
\hline Laryngotracheobronchitis & $\begin{array}{l}\text { Parainfluenza } \\
\text { virus (croup) }\end{array}$ & $\begin{array}{l}\text { Haemophilus influenzae } \\
\text { type B (epiglottitis) }\end{array}$ \\
\hline Tonsillitis & Rhinovirus & Group A Streptococcus \\
\hline Otitis media & $\begin{array}{l}\text { RSV, influenza } \\
\text { virus }\end{array}$ & $\begin{array}{l}\text { S. pneumoniae, } \\
\text { H. influenzae }\end{array}$ \\
\hline $\begin{array}{l}\text { Protracted bacterial } \\
\text { bronchitis }\end{array}$ & Not applicable & $\begin{array}{l}\text { Non-typable } H \text {. influenzae, } \\
\text { S. pneumoniae }\end{array}$ \\
\hline
\end{tabular}

Abbreviation: RSV, respiratory syncytial virus.

\section{Nursing strategies for supporting parents and carers}

Nurses have an important role in managing children with RTIs, both in the community and in the hospital environment. However, this role changes depending on the health infrastructure in different countries. In the UK, nurses are involved in managing children both in primary and secondary care, so are well placed for managing RTIs, one of the most common illnesses in childhood.

In primary care, practice nurses, community nurses, health visitors, school nurses, and pediatric nurse practitioners can often decide on further management and referral. ${ }^{52}$ In most cases, children with RTIs can be managed in the community with reassurance, advice on fluids, and antipyretics, and occasional prescription of antibiotics depending on clinical need. Table 3 will serve as an aide memoir. Cases where a serious pathology (eg, mastoiditis, bacterial tracheitis, epiglottitis) is suspected should be urgently referred to hospital for specialist management. Nurses also play an extended role in supporting parents who may be worried and anxious about their child's symptoms, by ensuring appropriate follow-up arrangements are provided, and that written and verbal safety net explanations are given and understood with regard to what should be done if the child deteriorates at home. Nurses also play an important role in encouraging uptake of immunization, which has been found to play a preventive role in development of further RTIs. ${ }^{2}$

In the hospital set up, nurses in the emergency department should identify sick children during triaging because they are often the first health care professional to come into contact with such patients. The triage nurse should identify the child with pre-terminal severe breathing difficulty and arrange immediate or urgent medical attention. ${ }^{52}$ Pre-terminal signs in a child with breathing difficulty are exhaustion, bradycardia, a silent chest, and significant apnea. ${ }^{52}$ Severe or life-threatening breathing difficulty is manifested by inappropriate drowsiness (difficult to rouse), agitation, and cyanosis in air. ${ }^{52}$

In the resuscitation situation, nurses in the emergency department will perform regular observations, administer respiratory support (eg, oxygen, continuous positive airway pressure) and medicines, ensure requested investigations are done, eg, a chest X-ray has been performed and acted upon. Nurses also need to ensure that parents are well supported in this vital period and are kept well informed about their child's progress. Some children who need to be transferred to the pediatric intensive care unit will need to be transported to specialist centers, and it is important that the transfer process happens smoothly and in a time-critical manner.

Once children have been stabilized in the emergency department, they will be transferred to the pediatric ward where their ongoing care will continue, including regular observations, ie, PEWS, administration of fluids and medicines, supporting nutrition, and personal hygiene. ${ }^{2}$ Communication with parents and ensuring that they feel involved in the care of their child is essential during this transition period. When the child is ready for discharge, nurses need to ensure that adequate supply of medicines are made available for continuing care. Signs of deterioration should be explained and the family should be informed of any hospital follow-up that has been arranged.

There is an increasing spectrum of nurse practitioner roles identified in pediatric care that have been evolving for many years. While some areas of respiratory care, such as asthma ${ }^{53,54}$ and cystic fibrosis, ${ }^{55,56}$ have well established nurse practitioner roles, these roles may not be that easily identified in the management of children with acute RTI in the hospital environment.

Community neonatal nurses supporting infants and families after discharge from neonatal intensive care units is another established area of practice where specialist nurses deliver respiratory care. ${ }^{31}$ Individual practice areas, such as the specialist nurse dealing with respiratory care in ex-premature babies, eg, CLD of prematurity, arranging home oxygen, providing nasogastric feeding support and palavizumab injections are a few areas where specialist nursing roles have been well established. ${ }^{16}$

Emergency departments and pediatric assessment units are seeing changes in medical practice with the emerging role of the advanced pediatric nurse practitioner. Advanced pediatric nurse practitioners are trained to a level where they can autonomously assess and manage children to the level of a medical professional, including ordering investigations, 


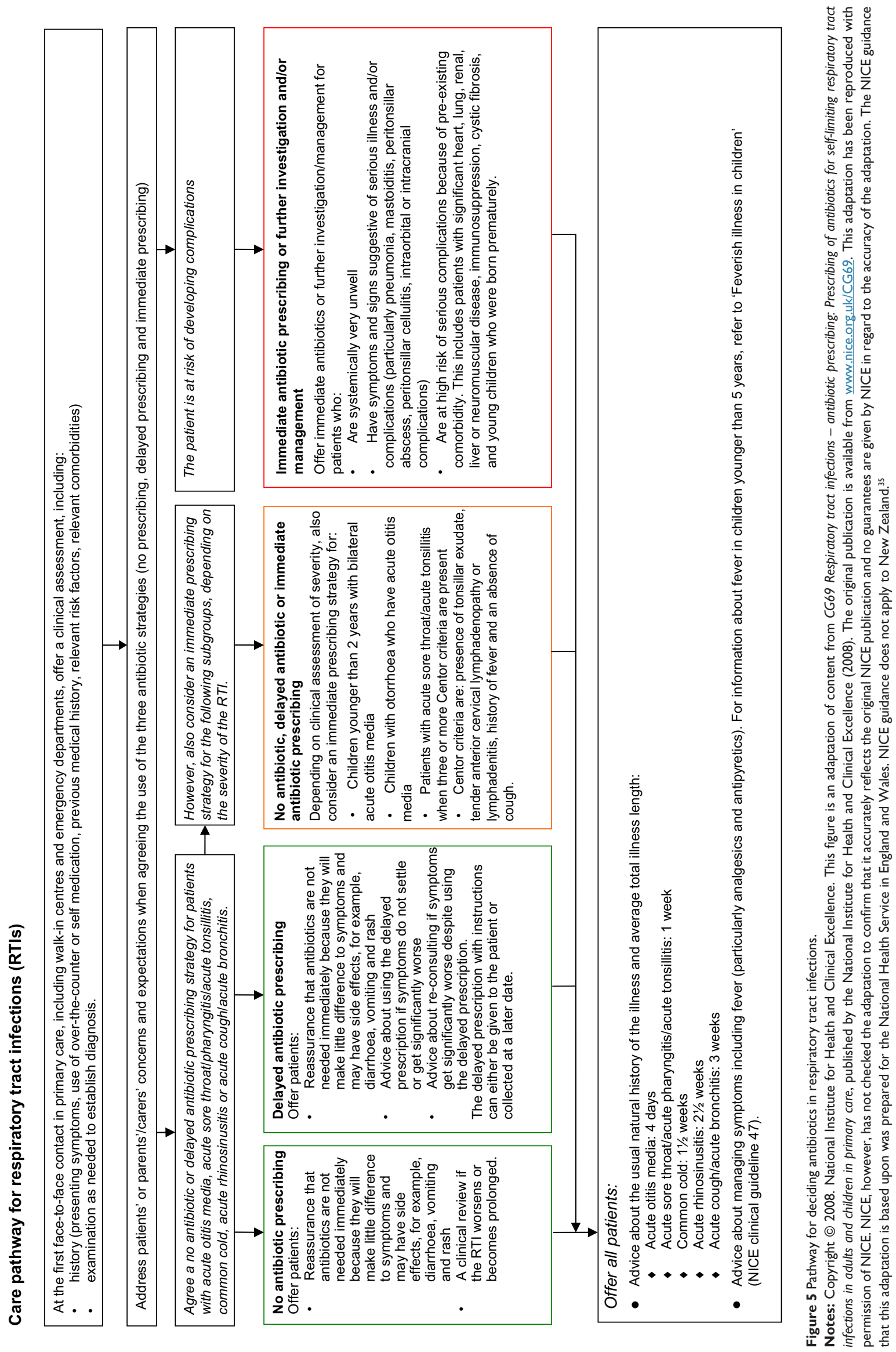




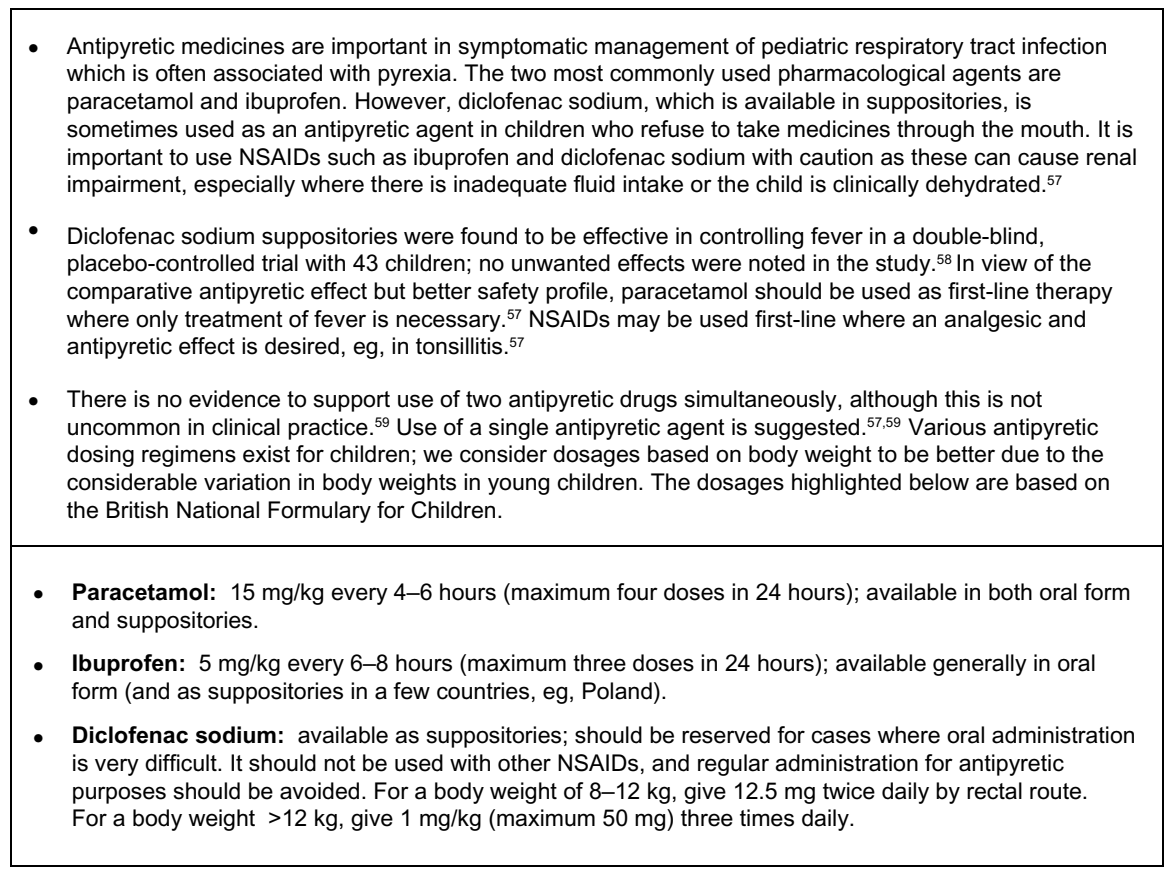

Figure 6 Antipyretic use in children.

Abbreviation: NSAIDs, non-steroidal anti-inflammatory drugs.

planning medical and nursing care, and prescribing medications, while also undertaking nursing care.

Another important aspect of managing RTIs in children is prescription of antibiotics (for bacterial RTIs). While it is important that antibiotics are prescribed with caution, as discussed previously, all prescribers, including non-medical prescribers, must have an understanding of where such prescriptions are likely to be beneficial. ${ }^{35}$ This knowledge will enable the practitioner to counsel families about the appropriateness of antibiotic therapy and reassure them when such therapies are not going to be of benefit to the child.

Guidelines published in 2008 by the National Institute for Health and Care Excellence ${ }^{35}$ outline a care pathway for common RTIs (Figure 5). However, the final decision regarding prescription of antibiotics lies with the clinician, and will be decided depending on the clinical condition of the patient. Figure 6 highlights the antipyretics commonly used in clinical practice and also the rationale for using single antipyretic agent.

\section{Conclusion}

RTIs in children are common in clinical practice. Health professionals in the community play an important role in managing children with reassurance, guidance on symptomatic management, and referring early where escalation of care is necessary. Nurses in the hospital environment need to deliver a holistic care package whereby both medical and emotional aspects are addressed. The role of nurse specialists is being increasingly recognized in some areas of respiratory care, and needs further expansion both in primary and secondary care. Included in this expanding role is the value of health promotion to educate families, thereby improving uptake of immunization, which has a role in preventing serious RTIs, such as epiglottitis and pneumonias.

\section{Disclosure}

The authors report no conflicts of interest in this work.

\section{References}

1. Schaad UB. Prevention of paediatric respiratory tract infections: emphasis on the role of OM-85. Eur Respir Rev. 2005;14:74-77.

2. Paul S, O'Callaghan C, McKee N. Effective management of lower respiratory tract infections in childhood. Nurs Child Young People. 2011;23:27-34.

3. Gill D, O'Brien N, editors. Paediatric Clinical Examination Made Easy. 5th ed. London, UK: Churchill Livingston; 2007.

4. NHS Choices. Respiratory tract infection. 2013. Available from: http:// www.nhs.uk/conditions/Respiratory-tract-infection/Pages/Introduction. aspx. Accessed June 20, 2014.

5. Harris M, Clark J, Coote N, et al. British Thoracic Society guidelines for the management of community acquired pneumonia in children: update 2011. Thorax. 2011;66(Suppl 2):ii1-ii23.

6. Scottish Intercollegiate Guidelines Network. Bronchiolitis in children. SIGN guideline 91. 2006. Available from: http://www.sign.ac.uk/pdf/ sign91.pdf. Accessed June 20, 2014.

7. Snellman L, Adams W, Anderson G, et al. Diagnosis and treatment of respiratory illness in children and adults. Bloomington, MN, USA: Institute for Clinical Systems Improvement; 2013. Available from: https:// www.icsi.org/_asset/1wp8x2/respillness.pdf. Accessed September 3, 2014.

8. Paranjothy S, Dunstan F, Watkins WJ, et al. Gestational age, birth weight, and risk of respiratory hospital admission in childhood. Pediatrics. 2013;132:e1562-e1569. 
9. Clark JE, Hammal D, Hampton F, Spencer D, Parker L. Epidemiology of community-acquired pneumonia in children seen in hospital. Epidemiol Infect. 2007;135:262-269.

10. Paul SP, Bains JK. Treating pneumonia in children. Independent Nurse. 2012:11; 24-27.

11. Finn R. To X-ray or not in child with signs of pneumonia. 2008. Available from: http://www.jfponline.com/fileadmin/content_pdf/ ped/archive_pdf/vol42iss7/70304_main.pdf. Accessed September 3, 2014.

12. Thomson A, Harris M. Community-acquired pneumonia in children: what's new? Thorax. 2011;66:927-928.

13. Leyenaar JK, Lagu T, Shieh MS, Pekow PS, Lindenauer PK. Variation in resource utilization for the management of uncomplicated communityacquired pneumonia across community and children's hospitals J Pediatr. 2014;165:585-591.

14. Nair H, Nokes DJ, Gessner BD, et al. Global burden of acute lower respiratory infections due to respiratory syncytial virus in young children: a systematic review and meta-analysis. Lancet. 2010;375:1545-1555.

15. Paul SP. The assessment and management of an infant with bronchiolitis. Journal of Health Visiting. 2013;1:86-88.

16. Whelan B. Nurse role in RSV management. Early Hum Dev. 2012; 88(Suppl 2):S29-S30.

17. McDougall P. Caring for bronchiolitic infants needing continuous positive airway pressure. Paediatr Nurs. 2011;23:30-35.

18. Gadomski AM, Scribani MB. Bronchodilators for bronchiolitis Cochrane Database Syst Rev. 2014;6:CD001266.

19. Teunissen J, Hochs AH, Vaessen-Verberne A, et al. The effect of $3 \%$ and $6 \%$ hypertonic saline in viral bronchiolitis: a randomised controlled trial. Eur Respir J. 2014;44(4):913-921.

20. Spurling GK, Doust J, Del Mar CB, Eriksson L. Antibiotics for bronchiolitis in children. Cochrane Database Syst Rev. 2011;6:CD005189.

21. Nagakumar P, Doull I. Current therapy for bronchiolitis. Arch Dis Child. 2012;97:827-830.

22. Brand PL, Baraldi E, Bisgaard H, et al. Definition, assessment and treatment of wheezing disorders in preschool children: an evidence-based approach. Eur Respir J. 2008;32:1096-1110.

23. Paul SP, Bhatt JM. Preschool wheeze is not asthma: a clinical dilemma. Indian J Pediatr. 2014;81(11):1193-1195.

24. van Woensel JB, van Aalderen WM, Kimpen JL. Viral lower respiratory tract infection in infants and young children. BMJ. 2003; 327:36-40

25. Bhatt JM. Recurrent wheeze in pre-school children. British Journal of Family Medicine. 2013;1:15-19.

26. Bjornson CL, Johnson DW. Croup in children. CMAJ. 2013;185: 1317-1323.

27. Narayanan S, Funkhouser E. Inpatient hospitalizations for croup. Hosp Pediatr. 2014;4:88-92.

28. Tibballs J, Watson T. Symptoms and signs differentiating croup and epiglottitis. J Paediatr Child Health. 2011;47:77-82.

29. Shargorodsky J, Whittemore KR, Lee GS. Bacterial tracheitis: a therapeutic approach. Laryngoscope. 2010;120:2498-2501.

30. Groothuis JR, Makari D. Definition and outpatient management of the very low-birth-weight infant with bronchopulmonary dysplasia. $A d v$ Ther. 2012;29:297-311.

31. O'Shea TM, Nageswaran S, Hiatt DC, et al. Follow-up care for infants with chronic lung disease: a randomized comparison of community- and center-based models. Pediatrics. 2007;119:e947-e957.

32. Parshuram CS, Duncan HP, Joffe AR, et al. Multicentre validation of the bedside paediatric early warning system score: a severity of illness score to detect evolving critical illness in hospitalised children. Crit Care. 2011;15:R184.

33. NHS Choices. Tonsillitis. 2011. Available from: http://www.nhs.uk/ Conditions/Tonsillitis/Pages/Introduction.aspx. Accessed June 24, 2014.

34. Scottish Intercollegiate Guidelines Network. Management of sore throat and indications for tonsillectomy - a national clinical guideline. Available from: http://www.sign.ac.uk/pdf/sign117.pdf. Accessed September 3, 2014.
35. National Institute for Health and Care Excellence Clinical Guidelines. Prescribing of antibiotics for self-limiting respiratory tract infections in adults and children in primary care. 2008. Available from: http://www. nice.org.uk/guidance/cg69/resources/cg69-respiratory-tract-infectionsfull-guideline3. Accessed September 3, 2014.

36. Hawes D, Linney MJ, Wilkinson R, Paul SP. Lemierre's syndrome: the importance of early detection. Br J Nurs. 2013;22:1075-1078.

37. Coticchia JM, Chen M, Sachdeva L, Mutchnick S. New paradigms in the pathogenesis of otitis media in children. Front Pediatr. 2013;1:52.

38. Jervis-Bardy J, Sanchez L, Carney AS. Otitis media in Indigenous Australian children: review of epidemiology and risk factors. $J$ Laryngol Otol. 2014;128(Suppl 1):S16-S27.

39. Ryborg CT, Søndergaard J, Lous J, et al. Factors associated with antibiotic prescribing in children with otitis media. ISRN Family Med. 2013;2013:587452.

40. Goossens H, Ferech M, Vander Stichele R, Elseviers M; ESAC Project Group. Outpatient antibiotic use in Europe and association with resistance: a cross-national database study. Lancet. 2005;365:579-587.

41. National Institute for Health and Care Excellence CKS. Otitis media - acute. 2009. Available from: http://cks.nice.org.uk/otitis-mediaacute\#!scenariorecommendation:2. Accessed May 7, 2014.

42. Paul SP, Wilkinson R. The importance of recognising mastoiditis in children. Nurs Times. 2012;108:3.

43. Craven V, Everard ML. Protracted bacterial bronchitis: reinventing an old disease. Arch Dis Child. 2013;98:72-76.

44. Paul SP, Hilliard T. The importance of recognizing protracted bacterial bronchitis in children. Indian J Pediatr. 2014;81:1-3.

45. Marchant J, Masters IB, Champion A, et al. Randomised controlled trial of amoxycillin clavulanate in children with chronic wet cough. Thorax. 2012;67:689-693.

46. Mackenzie KJ, Anderton SM, Schwarze J. Viral respiratory tract infections and asthma in early life: cause and effect? Clin Exp Allergy. 2014;44:9-19.

47. Nafstad P, Magnus P, Jaakkola JJ. Early respiratory infections and childhood asthma. Pediatrics. 2000;106:E38.

48. Khetsuriani N, Kazerouni NN, Erdman DD, et al. Prevalence of viral respiratory tract infections in children with asthma. J Allergy Clin Immunol. 2007;119:314-321.

49. Zomer-Kooijker K, Uiterwaaal CS, Verschueren KJ, et al. Respiratory tract infections and asthma control in children. Respir Med. 2014;101(10):1446-1452.

50. Ahanchian H, Jones CM, Chen YS, Sly PD. Respiratory viral infections in children with asthma: do they matter and can we prevent them? BMC Pediatr. 2012;12:147.

51. Lakhanpaul M, Stephenson T, MacFaul R, Werneke U. A clinical guideline for the management of children presenting with acute breathing difficulty. 2004. Available from: http://www.rcpch.ac.uk/sites/default/files/ asset_library/Research/Clinical\%20Effectiveness/Endorsed\%20guidelines/ Children\%20Presenting\%20with\%20Acute\%20Breathing\%20Difficult Breathing\%20difficulty\%20guideline.pdf. Accessed September 3, 2014.

52. Fabrellas N, Vidal A, Amat G, Lejardi Y, del Puig Deulofeu M, Buendia C. Nurse management of 'same day' consultation for patients with minor illnesses: results of an extended programme in primary care in Catalonia. $J$ Adv Nurs. 2011;67:1811-1816.

53. Kuethe M, Vaessen-Verberne A, Mulder P, Bindels P, van Aalderen W. Paediatric asthma outpatient care by asthma nurse, paediatrician or general practitioner: randomised controlled trial with two-year follow-up. Prim Care Respir J. 2011;20:84-91.

54. Tolomeo C. Toward better clinical asthma management. The nurse practitioner as asthma educator. Adv Nurse Pract. 2007;15:26-32.

55. Brown RF, Willey-Courand DB, George C, et al. Non-physician providers as clinical providers in cystic fibrosis: survey of US programs. Pediatr Pulmonol. 2013;48:398-404.

56. Vandenbranden SL. The role of the nurse practitioner in the care of children with chronic respiratory disorders. Pediatr Ann. 2010;39: 800-804.

57. Litalien C, Jacqz-Aigrain E. Risks and benefits of nonsteroidal antiinflammatory drugs in children: a comparison with paracetamol. Paediatr Drugs. 2001;3:817-858. 
58. Polman HA, Huijbers WA, Augusteijn R. The use of diclofenac sodium (Voltaren) suppositories as an antipyretic in children with fever due to acute infections: a double-blind, between-patient, placebo-controlled study. J Int Med Res. 1981;9:343-348.

59. Banks T, Paul SP, Wall M. Managing fever in children with a single antipyretic. Nurs Times. 2013;109:24-25.
60. Advanced Life Support Group. Advanced Paediatric Life Support: The Practical Approach, 5th Edition. edited by Martin Samuels, Susan Wieteska. 2011.

Nursing: Research and Reviews

\section{Publish your work in this journal}

Nursing: Research and Reviews is an international, peer-reviewed, open access journal publishing original research, reports, reviews and commentaries on all aspects of nursing and patient care. These include patient education and counselling, ethics, management and organizational issues, diagnostics and prescribing, economics and

resource management, health outcomes, and improving patient safety in all settings. The manuscript management system is completely online and includes a very quick and fair peer-review system. Visit http://www.dovepress.com/testimonials.php to read real quotes from published authors. 